\title{
INTEGRAÇĀO DA DISCIPLINA ENFERMAGEM PEDIÁTRICA NO CURRÍCULO DO CURSO DE GRADUAÇÃO DA ESCOLA DE ENFERMAGEM DA USP *
}

\author{
Esther Moraes** \\ Dyrce Maria Rocha Martins $*: * *$ \\ Margareth Angelo **** \\ Tania Regina Storto Moleiro*****
}

MORAES, E.; MARTINS, D. M. R.; ANGELO, M.; MOLEIRO, T. R. S. A integração da disciplina Enfermagem Pediátrica no currículo do Curso de Graduação da Escola de Enfermagem da USP. Rev. Esc. Enf. USP, São Paulo, 15(1):69-71, 1981.

As autoras apresentam a realidade do ensino de Enfermagem Pediátrica, na Escola de Enfermagem da USP, apresentando as dirctrizes dos professores determinando o caráter da disciplina em diferentes periodos.

Oferecemos ao I Encontro Nacional de Educação em Enfermagem, promovido pela Associação Brasileira de Educação em Enfermagem, a nossa realidade de ensino de Enfermagem Pediátrica na Escola de Enfermagem da USP.

Propomos aos colegas docentes atenção para refletirem sobre as implicações das diretrizes do professor no ensino da enfermagem.

O sentido desta proposição é, expondo a nossa experiência para os participantes deste encontro, criar um clima favorável a fim de encontrarmos um forte elemento integrador para a assimilação de Enfermagem Pediátrica pelos estudantes.

Neste trabalho pretendemos focalizar as opiniões e sugestões das alunas e as nossas crenças e tomadas de consciência que surgiram no período de 1969 a 1978 . Assim, apresentamos no quadro I os fatores que, temos consciência, influíram nas programações da disciplina neste periodo.

As diretrizes centrais das docentes da diciplina em Enfermagem Pediátrica, no período de 69 a 78, em relação ao ensino, foram:

- reconhecer onde estavam as maiores dificuldades para os alunos: comprcensão e aceitação das manifestações da criança, dos pais e dos estudantes;

- identificar as unidades do programa com as: atribuições da função assistencial da enfermeira em pediatria;

- organizar experiências e tarefas adequadas aos: fenômenos predominantes num campo de prática de enfermagem, para estimular nos alunos a CONDUTA refletida.

* Trabalho apresentado no I Encontro Nacional de Educação em Enfermagem promovido pela Associação Brasileira de Educação em Enfermagem, de 27 a 30 de abril de 1979, em São Paulo.

** Professor Assistente Doutor da disciplina Enfermagem Pediátrica da EEUSP.

*** Professor Assistente da disciplina Enfermagem Pediatrica da EEUSP. Mestre em Enfermagem.

$\star \star * *$ Auxiliar de Ensino da Disciplina Enfermagem Pediátrica da EEUSP.

***** Enfermeira Instrucional da disciplina Enfermagem em Doenças Transmissíveis e Enfermagem Pediátrica da Escola de Enfermagem da Universidade de Taubaté. 
Concluindo, esclarecemos que o intuito de nossa apresentação não é buscar um julgamento mas convidar os colegas a refletirem sobre as implicações no ensino de enfermagem, a partir do que o professor pensa.

Propomos, então, a seguinte indagação:

“Quando você ensina, qual a sua maior preocupação?" A nossa é tornar viva a satisfação de viver.

\section{QUADRO I}

FATORES QUE DETERMINARAM O CARATER DA DISCIPLINA NO PERIODO 69.78

\begin{tabular}{ll}
\hline Epoca & Fatores \\
\hline & FATOR DESENCADEANTE \\
Levantamento entre as estudantes das DIFICULDADES encontradas no cuidado da \\
criança, semana por semana (8). \\
CRENÇAS DAS DOCENTES DA DISCIPLINA \\
- Que as estudantes não apresentavam dificuldade em compreender a patologia \\
própria da criança. \\
- Que a CRIANÇA representava um tema de estudo complexo para ser ENTEN- \\
DIDO e ACEITO em todos os seus aspectos. \\
- Que a programação deveria favorecer a associação entre teoria e prática. \\
- Que os estudos de enfermagem pediátrica careciam de sistematização.
\end{tabular}

DIRETRIZ

1969 Programar EXPERIENCIAS DE CAMPO que refletissem dificuldades e cuja solução dependesse mais de MUDANÇAS de ATITUDE do que de aquisição de co. nhecimentos e habilidades. MORAES (1969).

\section{FATOR DESENCADEANTE}

1970 e 1971 Leitura da bibllografia americana sobre enfermagem pediátrica, especialmente pesquisas.

Experiências das docentes na assistência de crianças hospitalizadas.

TOMADA DE CONSCIENCIA DAS DOCENTES

- Importância dos problemas psicológicos enfrentados pela criança e por seus familiares, resultantes da hospitalização.

- Possibilidade de dar OBJETIVIDADE às atividades das estudantes, graças aos parâmetros sobre manifestaçōes de crianças, pais e enfermeira, aos métodos e abordagens encontrados na bibliografia.

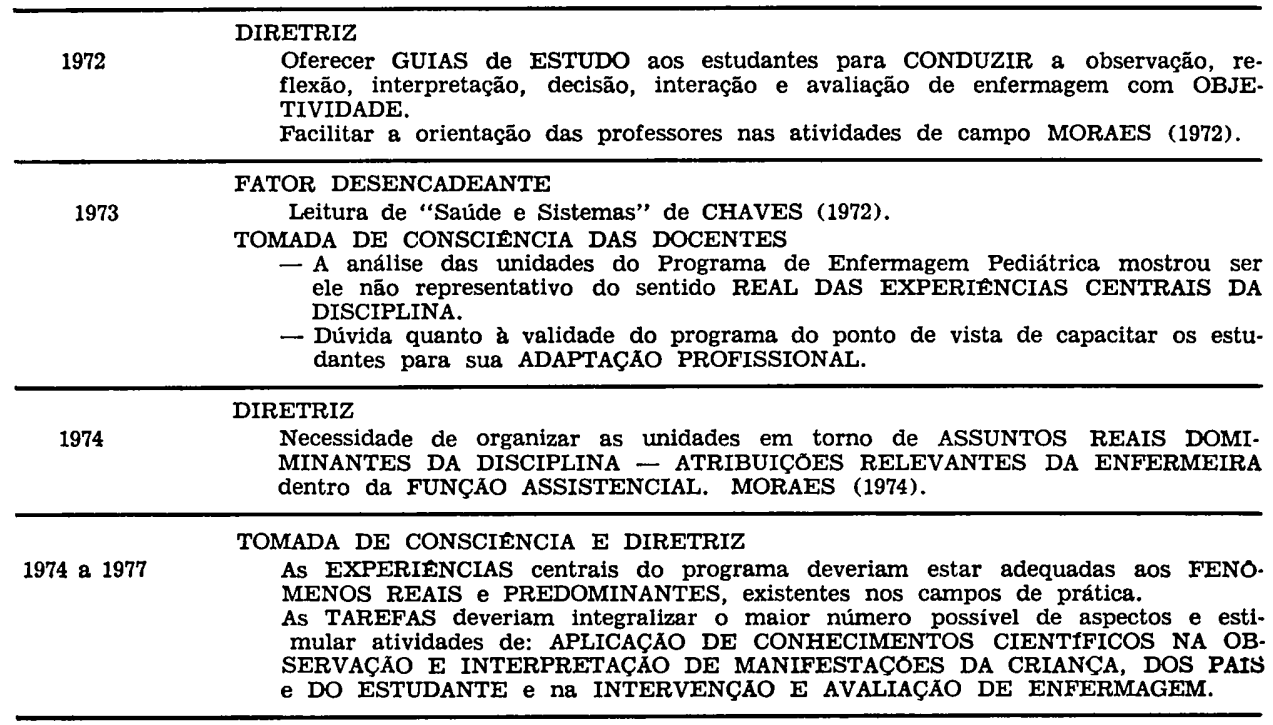


MORAES, E.; MARTINS ,D. M. R.; ANGELO, M.; MOLEIRO, T. R. S. The integration of Pediatric Nursing in basic course of Nursing School of São Paulo University. Rev. Esc. Enf. USP, São Paulo, 15(1):69-71, 1981.

The authors describe the development of the teaching of Pediatric Nursing at the University of São Paulo, School of Nursing, as well as the teachers beliefs which determined the system of teaching in diferent chronological periods.

\section{REFERENGIAS BIBLIOGRAFICAS}

MORAES, E. Programaçōes de experiências de alunos em enfermagem pediátrica. Rev. Esc. Enf. USP, São Paulo, 3(2): 3-32, 1969.

MORAES, E. Guias de estudo de enfermagem pediátrica. Rev. Esc. Enf. USP, São Paulo, 6(1-2): 7-128, 1972. MORAES, E. Atividades discentes e docentes organizadas a partir das funções da enfermeira de pe diatria. Rev. Bras. Enf., Rio de Janeiro, 26(6): 419-424, 1973. 